ARTIGO

Recebido em: $31 / 08 / 2018$

Aceito em: $31 / 10 / 2018$

\title{
Uma Caminhada pela Cidade: reflexões sobre informação e memória na cidade a partir de um poema de Charles Baudelaire
}

\author{
A Walk for the City: reflections on information and memory in the \\ city from a poem by Charles Baudelaire
}

\author{
Tahis Virginia Gomes da SILVA (tahis22silva@gmail.com)* \\ José Mauro Matheus LOUREIRO (jmmloureiro@gmail.com) ** \\ * Doutoranda do Programa de Pós-Graduação em Ciência da Informação da Universidade Federal da \\ Paraíba e Bibliotecária-documentalista Coordenadora da Biblioteca Setorial do Centro de Ciências da \\ Saúde da Universidade Federal da Paraíba. \\ ** Professor Associado IV da Universidade Federal do Estado do Rio de Janeiro e Professor \\ permanente do Programa de Pós-Graduação em Ciência da Informação da Universidade Federal da \\ Paraíba.
}

\section{Resumo}

O caminhar pela cidade, numa analogia com o ato de escrever, é um traçar de percursos e trajetórias construindo a tessitura informacional dos sujeitos no espaço da cidade, por meio dos caminhos delineados pelo citadino, enquanto ator social. Este artigo apresenta uma reflexão sobre a construção da informação através do ato de caminhar pelas ruas da cidade urbana a partir da análise do poema de Charles Baudelaire "A Uma Passante" perpassando pela compreensão da cidade como espaço de representação e enquanto artefato inforcomunicacional memorialístico e de expressão cultural dos sujeitos sociais através de uma revisão de literatura fundamentada na inter-relação Informação / Memória. Trata-se de fragmentos da fundamentação teórica que embasarão uma proposta de tese em construção desenvolvida no âmbito de um programa de Ciência da Informação.

Palavras-chave: Informação - Cidade Urbana. Cidade - Espaço de Memória. A Uma passante Charles de Baudelaire. Cidade - Artefato infor-comunicacional memorialístico.

\begin{abstract}
Walking through the city, in an analogy with the act of writing, is a tracing of paths and paths by constructing the informational content of the subjects in the city space, through the paths outlined by the city as a social actor. This article presents a reflection on the construction of the information through the act of walking through the streets of the urban city from the analysis of the poem of Charles Baudelaire "A Uma Passante", passing through the understanding of the city as a space of representation and as a memorialistic infor-communicational artifact and cultural expression of social subjects through a literature review based on the Information / Memory interrelationship. These are fragments of the theoretical foundation that will base a proposal of thesis under construction developed in the scope of an Information Science program.
\end{abstract}

Keywords: Information - Urban City. City - Memory Space. A Passant - Charles de Baudelaire. City Memorialistic infor-communicational artifact.

v. 24, n. $54,2019$. p. $135-146$

ISSN 1518-2924

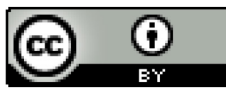




\section{INTRODUÇÃo}

$\mathrm{Na}$ contemporaneidade ocidental o ato de caminhar pelas ruas, desbravando a cidade, vem sendo substituindo pelo hábito de circular pelos corredores dos "espaços de consumo", especialmente nos ambientes dos Shoppings Centers, quando, em busca de uma falsa sensação de segurança, se abdica da liberdade de escolha e das relações sociais e tenta-se ignorar a ação do tempo sobre as decisões da vida urbana numa realidade em um "pseudopaís de maravilhas", num universo paralelo onde "a substituição de 'ser' por 'ter' [...]" (BAUMAN, [2014], p.29) assume status de superioridade nas relações de convívio dos sujeitos sociais, uma vez que na contemporaneidade "somos o que temos ou aparentamos ter" e a aparência das coisas seduz e convence muito mais rápido do que sua essência.

Neste artigo se apresentam algumas considerações sobre os termos Informação e Memória por meio de uma reflexão sobre o ato de caminhar pelas ruas da cidade urbana - compreendendo a cidade como artefato infor-comunicacional memorialístico - através da análise interpretativa dos versos do poema "A Uma Passante" de Charles de Baudelaire, perpassando por uma revisão de literatura sobre as inter-relações informação e memória - enquanto representação social - dentro do contexto da criação de significados e ressignificados dos sujeitos sociais. Trata-se de uma pesquisa de abordagem qualitativa, do tipo explicativa.

\section{CAMINHAR PELAS RUAS: universo informacional}

Numa comparação com o texto escrito é possível firmar que o ato de caminhar constrói a escrita do passante. Onde em cada passo dado, cada trajetória percorrida, cada decisão em ir por esta e não àquela rua, em cortar por certo caminho e no virar em uma esquina qualquer, às vezes se deparando com obstáculos ou limites, como muros e curvas sinuosas, o sujeito social ressignifica as informações que lhe chegam aos olhos (CERTEAU, [2014])

Diariamente é apresentada aos sujeitos sociais uma infinidade de informações nos mais diversificados suportes, formatos, veículos e fluxos informacionais, convidando os envolvidos, e até mesmo os obrigando, a selecionar, mesmo que inconscientemente, aquilo que será descartado, assimilado ou reconfigurado e ressignificado em suas práticas sociais.

Os sujeitos sociais são produtores e consumidores de informação, definindo novos conceitos fazem novas leituras e revisitam conceitos apresentados (FREIRE; FREIRE, 2009), seguindo em frente, porém, às vezes olhando um pouco para trás, em um anseio permanente por recuperar a informação perdida.

Esta inquietação, que os leva a busca de conhecimento, utilizando uma grande quantidade de mecanismos e estratégias de recuperação e estocagem de informação é constante no desenvolvimento da humanidade diante do contexto da diversidade cultural (PINHEIRO, 2011; MCGARRY, 1999).

Informação é uma palavra que remete a ideia de ordenamento, de classificação, de organização, e, sobretudo, de redução de incertezas (MCGARRY, 1999). Portanto, é possível afirmar que, no contexto da contemporaneidade, a informação é "a mais poderosa força de transformação" e desenvolvimento do gênero humano (ARAÚJO, 1991, p. 37).

No simples caminhar pelas ruas de uma cidade ou de um bairro qualquer é construído uma imensidade de representações que constituirão a memória dos sujeitos envolvidos, uma vez que "[...] a cada instante, há mais do que o olho pode ver, mais do que o ouvido pode perceber, um cenário ou uma paisagem esperando para ser explorados [...]." (LYNCH, 2006, p. 1), onde, na cidade, com suas ruas e logradouros, um universo de significações infor-comunicacionais não cessa de se apresentar e se reconfigurar.

Refletido no verso "A rua em derredor era um ruído incomum [...]" (BAUDELAIRE, 1857) é possível perceber que no caminhar pela cidade a informação chega não apenas aos olhos, mas por todos os sentidos. São sons, cheiros e sensações diversas que impregnam a vida dos transeuntes num dinâmico movimento de transformação contínua.

A informação nas cidades se apresenta muitas vezes em um emaranhado de dados, tornando necessário estabelecer ou utilizar algum mecanismo de ordenação para que a informação seja identificada, seja codificada, seja objetivada. 
A partir dessa explanação se pode compreender a informação como a ação de ordenar "as coisas" - no sentido do objeto material em si e no sentido das ideias organizando tudo dentro de um processo de classificação e representação (MCGARRY, 1999). Ou ainda, conforme o vocabulário latino informare, informação designa o sentido de "dar forma, ou aparência, por em forma, formar, [...] representar, apresentar, criar uma idéia [...]." (ZEMAN, 1970, p. 156). Sendo assim, se pode afirmar que a informação está relacionada à configuração física, a objetivação, a materialidade.

A informação pode, então, ser compreendida como fundamental instrumento de estímulo do desenvolvimento entre as sociedades, possibilitando acima de tudo mais qualificação profissional e acesso a uma melhor qualidade de vida (ALMEIDA, GUIMARÃES, 2007).

A informação se manifesta sob o aspecto da materialização do conhecimento onde se pode afirmar que "information is defined as a physical surrogate of knowledge (e.g. language) used for communication.” (FARRADANE, 1980, p. 77). Mas, também como organização ou ordenação das coisas, onde a informação é representada através de:

[...] estruturas, formas, modelos, imagens e configurações, em idéias, ideais e ídolos, em índices, imagens e ícones, no comércio e na mercadoria; em continuidade e descontinuidade, em sinais, signos, significantes e símbolos; em inflexões; em presenças e ausências; em palavras, em ações, em silêncios [...]. (SILVA; RIBEIRO, 2002 citado por ROBREDO, 2003, p.4).

Logo, a informação tem um caráter de multiplicidade, um conceito polissêmico, conforme a atribuição que cada sujeito e, sobretudo, cada sociedade, lhe confere.

Portanto, a informação acontece na tessitura das inter-relações socioculturais, onde cada sociedade configura o que é relevante para seu grupo, dentro de determinado contexto histórico, estabelecendo o que é essencial e significativo para sua realidade sociocultural (SILVA, 2006).

Consequentemente, compreendendo a palavra informação como artefato, ou seja, como construção humana, para que esta exista deve ser significativa, perpassando dentro de uma situação de representação, onde a informação tem sentido, é significativa e por sua vez é significante para os sujeitos, afirmando-se que as pessoas atuam "[...] num mundo de significados, [...] criam significados, compartilham significados, transmitem significados, e tendem a temer a falta de significado como uma privação terrível." (MCGARRY, 1999, p. 32). Portanto, informação é atribuição de sentidos, pois "atribuímos significado ao nosso mundo ao identificar e relacionar classes de eventos ao invés de casos individuais [...]." (MCGARRY, 1999, p. 32). Porém, não se resume a criação de sentidos meramente de forma pessoal, individual, mas, sobretudo, a dar sentidos diante do fenômeno social.

Afirma-se, assim, o caráter de representabilidade da informação, como uma produção humana. Reconhecendo o potencial humano - sobretudo, do ser humano enquanto "ser e ator social" - no processo de criação de artefatos infor-comunicacional (AZEVEDO NETTO, 2007, p.5).

Enfim, se pode definir informação como:

[...] a qualidade da realidade material de ser organizada [...] e sua capacidade de organizar, de classificar um sistema [...]. É, juntamente com o espaço, o tempo e o movimento, uma outra forma fundamental de existência da matéria [...]. Não é um princípio que existiria fora da matéria e independentemente dela [...] e si inerente a ela, inseparável dela. (ZEMAN, 1970, p. 157).

Dessa maneira, se pode afirmar a informação como artefato, produção humana, que surge, sobretudo, das representações que os sujeitos fazem dos fenômenos sociais (AZEVEDO, 2007), ou ainda, conforme argumenta Buckland (2012), a informação-comocoisa manifesta por meio dos suportes materiais ou materializados, como aquilo que referencia algo, enfatizando-se seu caráter de materialidade. 
2.1 CAMINHANDO PELAS RUAS DA CIDADE: espaço de construção de representações

A cidade é caracterizada pela contradição permanência e transitoriedade. Onde o movimento do ir e vir dos transeuntes se contrapõe a estabilidade de suas construções, a rotina de seu cotidiano urbano; esta é a dinâmica da cidade.

A cidade é lugar de construção de sentidos e representações, "[...] uma construção no espaço" (LYNCH, 2006, p. VII) onde as relações entre tempo e espaço são perceptíveis em cada passo que o caminhante dar, cada esquina, cada viela ou beco em que informações são apresentadas aos transeuntes, denotando o movimento contínuo da cidade.

A cidade urbana está sempre em construção, em um dinâmico processo de criação de sentidos, sempre seguindo em frente, em um "[...] movimento dialético, contraditório, que se apresenta frente aos olhos todos os dias [...], carregados de memória de si mesmos e dos outros, dos lugares e de lugar nenhum [...]" (SOUZA, 2017, p. 22) lugar de encontros e desencontros de estranhos, com relações transitórias sem passado e sem futuro (BAUMAN [2014]) possibilitando perceber a cidade "como um celeiro de pesquisa e produção constante do devir." (SOUZA, 2017, p. 15), um lugar de possibilidades.

Os espaços públicos das cidades promoveram as inter-relações entre os sujeitos como atores sociais - uma vez que "o sujeito não pode emergir senão da sociedade [...]" (DEBORD, 2003, p.38) - e produtores e consumidores de informação, onde ruas, avenidas, logradouros, praças etc., possibilitando "as formas de sociabilidade [que] tinham - e ainda têm - influência sobre a distribuição e até mesmo sobre a produção do conhecimento" (BURKE, 2003, grifo nosso), ou melhor, sobre a produção de artefatos infor-comunicacionais.

A cidade é a cima de tudo, "um lugar de produção e de trocas" de informação (LE GOFF, 1998, p.25). E, com o aumento da busca por informação e por serviços informacionais a cidade torna-se a cada dia um espaço de circulação e acesso de informação, e, sobretudo, de construção de conhecimentos.

A cidade, sobretudo, no contexto urbano, possui uma multiplicidade de funções, sendo um organismo vivo, em permanente transformação, e como um "fenômeno atemporal" (LYNCH, 2006, p. 182) a cidade urbana, evolui ou "morre" sob a ação das intempéries do tempo.

Há uma diversidade de lugares nas cidades contemporâneas que podem ser denominados por "espaços públicos". Logo essa vasta variedade tipológica, distribuindo principalmente por tamanhos, compõe um conjunto de categorias. Cada categoria se distância de padrão ideal de espaço civil indo em direção opostas que, no entanto, se complementam (BAUMANN, [2014]).

Na cidade, a memória e a informação dialogam em cada recanto, em cada lugar, em cada artefato monumental que se insere no contexto do espaço público, possibilitando investigar a cidade, consciente que "[...] É preciso olhar e sentir a cidade, apreciando seus cheiros, seus odores, seus sabores. [...] É necessário caminhar pelas ruas conhecidas e desconhecidas [...]." (SOUZA, 2017, p.26) analisando o discurso impessoal, desbravando e redescobrindo a cidade, observando nuanças que passam despercebidas do olhar muitas vezes indiferente do sujeito urbano cosmopolita diante das efemeridades cotidianas. É precisar reencontrar o encanto pela "vida desse meu lugar"1.

Porém, deve-se observar principalmente cada encontro entre sujeitos sociais no espaço da cidade, estranhos que se cruzam no vai e vem da vida fugaz, nos ditos tempos feroz de nossas sociedades contemporâneas, nesta contemporaneidade líquida que escorre por entre os dedos, se esvaindo como a fumaça das antigas Marias-fumaças que se desmanchavam no ar, mas, deixava na atmosfera, em um misto de perfume e odor, a sensação do que um dia fora ou do que poderia ser (CERTEAU, [2014]; BAUMAN, [2014]).

\subsection{A CIDADE COMO LUGAR DE MEMÓRIA: breves considerações}

Cada cidade tem sua fisionomia, seu traçado, seu delinear territorial, que apresenta sua identidade enquanto espaço de construção social em constante transformação, mas, além de ser um fenômeno espacial "a percepção da cidade é, em essência, um fenômeno temporal [...]" (LYNCH, 2006, p.182) cada sujeito social atribui aos lugares da cidade uma gama de

\footnotetext{
${ }^{1}$ Trecho da música Encontro e Despedidas composição de Fernando Brant e Milton Nascimento ([19--]).
} 
significações onde cada lembrança é relacionada a um lugar, a algo vivenciado. E como "uma cidade é uma organização mutável e polivalente, um espaço com muitas funções, erguida por muitas mãos, num período de tempo [...]." (LYNCH, 2006, p.101), as cidades se configuram no tempo e como campo de representação, e, portanto, de construção de memórias.

Na cidade, os espaços e os lugares de interação social são campos de construção de memórias individuais e coletivas que possibilitam esse encontro duplo numa convivência simultaneamente em cada sujeito social (HABSWACHS, 2008).

Diante das duas principais características da memória, a saber: seu caráter de seletividade, e com isso, sua incapacidade de registrar tudo ou de armazenar e recuperar tudo o que foi registrado; e sua possibilidade de ser manipulada ou produzida, ou seja, seu potencial de ser induzida (MENESES, 2002, p.183), no caminhar pela cidade, esses aspectos, unidos ao dinamismo e a mutabilidade da memória, se confirmam. Uma vez que, ao caminhar pelas vias de uma cidade, o sujeito social elabora um novo mapeamento do espaço que percorre, estabelecendo associações múltiplas e criando novos caminhos muitas vezes diversos dos preestabelecidos pelos cartógrafos da cidade, numa seleção dinâmica, contínua e imprevisível.

Afirmando que "a memória gira em torno de um dado básico do fenômeno humano, a mudança" (MENESES, 2002, p.185), ou seja, a memória não se estagna no tempo do passado, estando em permanente transformação, na cidade, e, sobretudo, no contexto do meio urbano, evidencia-se este aspecto de mutabilidade da memória.

Le Goff (1996) aponta que a memória inicialmente se apresenta sob duas categorias de sociedades: as sociedades orais e as sociedades da escrita. E, partindo de sua definição de memória como a capacidade "de conservar certas informações, [...] às quais o homem pode atualizar impressões ou informações passadas, ou que ele representa como passadas" (LE GOFF, 1996, p.423) a construção das memórias na cidade ocorrem tanto pela troca de informação, quer sejam orais quer sejam textuais ou hipertextuais, e mais atualmente pelas formas de comunicação audiovisuais presentes em cada canto e recanto da cidade.

Logo, compreende-se a memória como um fenômeno representacional, um organismo vivo, ultrapassando a noção inicial de memória individual percebe-se a memória enquanto construção social, um testemunho do vivido, uma releitura do vivenciado, permanentemente atrelado ao tempo, que se renova e lhe concedendo seu caráter dinâmico e de ressignificação contínua (AZEVEDO NETTO, 2005; RIBEIRO, [2000]).

Com isso, a memória se caracteriza primordialmente como um ato de continuidade. Isto porque a memória não diferencia, não realiza recortes entre passado e presente, mesmo que remeta ao passado, o tornar presente ou o atualizar através do ato de lembrar/relembrar. E, uma vez que "não existem lembranças estáticas" a memória apresenta-se como um "celeiro de possibilidades", em processo de constante construção dinâmica (RIBEIRO, [2000]).

Le Goff (1996, p. 423) levanta algumas características presentes no conceito de memória, destacadas nas expressões "atualizar impressões ou informações passadas, ou que ele representa como passadas" de onde se pode afirmar que memória é um processo de seleção, um recorte e uma colagem daqueles eventos que são mais significativos, ou seja, é um processo de classificação do ser humano; enfatizando o aspecto da seletividade da memória apontado por Catroga (2001).

A memória, então, é também um ato de representação, ressaltando-se as experiências que o sujeito vivenciou e procura atualizar individual ou coletivamente. Sendo possível, consequentemente, afirmar a memória com um processo em constante e dinâmica transformação, uma construção representacional do sujeito social.

Uma vez que a memória necessita de suportes que possibilitem sua materialidade, a exemplos das linguagens, dos signos, dos espaços, das diversas formas de registro (enquanto documentação), é possível afirmar que a memória está subordinada a materialidade (CATROGA, 2001 e nas cidades essa objetivação nos envolve em cada esquina, sendo "[...] preciso entender que o conhecimento que emana da cidade ultrapassa suas edificações, avenidas e calçadas" (SOUZA, 2017, p.15) onde até a iluminação artificial dos postes em um fim de tarde induz e conduz o olhar, a vegetação em um canto do meio fio nos chama a atenção e pode nos remeter a um acontecimento vivenciado naquele lugar ou mesmo em outro lugar, do qual se referencia. 
A memória se define a partir das representações que o sujeito social faz de suas vivências, sua significação do mundo que o cerca e na cidade - espaço de dinamismo e desbravamento - onde os fenômenos culturais se apresentam em todos os lugares e aonde esse leque de representações é ampliado (SOUZA, 2017).

A memória "significa experiências consistentes, ancoradas no tempo passado facilmente localizável [...] constitui-se de um saber, formando tradições, caminhos [...]." (DIEHL, 2002, p.116), portanto, a memória, sobretudo, no caminhar na cidade, é permanentemente atualizada e ressignificada.

$\mathrm{Na}$ cidade as experiências vivenciadas pela coletividade ou pelos grupos aos quais os sujeitos pertencem, tem um destaque maior, pois o espaço da cidade é, sobretudo, um espaço público, que induz a convivência coletiva. E nesse contexto, de inter-relação da memória na cidade numa relação fundamentalmente coletiva, há um processo de "projeção ou de identificação", no qual a relação do sujeito com o advento vivenciado no coletivo é tão fortemente arraigado que mesmo não tendo vivenciado pessoalmente determinado fato, este adquire uma significação tão forte, sendo possível adotar a expressão "memória por herança" (POLLACK, 1992).

Em um empenho em manter viva a experiência do vivido que se ancora no passado e alicerça no presente expresso através dos artefatos infor-comunicacionais da cultura material se pode definir memória como "[...] aquele conjunto de eventos, fatos, personagens que, através da sua existência no passado, detêm experiências consistentes para o estabelecimento de uma relação de atualidade [...]" (OLIVEIRA; AZEVEDO NETTO, 2007, p. 32) experiências essas que se expressam diariamente na vida das grandes cidades.

A memória - como o caminhar pelas ruas da cidade - cria seus próprios percursos, inventando novos caminhos para reencontrar os resquícios do vivido, constrói seus próprios mecanismos de recuperação, algo que às vezes nos dá a impressão do "eu já estive aqui" aquela sensação de déjà vu ao passar por uma rua ou observando um detalhe de uma fachada de uma edificação numa ruína qualquer. Este é o aspecto do fenômeno construído socialmente e individualmente, seu potencial de construção e reconstrução contínua de significados e ressignificados, sobretudo, na dinâmica e fugaz vida cotidiana dos grandes centros urbanos.

2.3 A CIDADE NA MODERNIDADE: uma breve reflexão sobre o poema "A Uma Passante" de Baudelaire

Os lugares e os locais - compreendidos como espaços de memória (LOUREIRO, 2015) - refletem a memória social dos sujeitos que se envolvem em sua construção. Contudo, extrapolando as práticas da vivência pessoal, a memória ruma a uma construção de significação sociocultural, em razão de que "mesmo quando os locais não têm em si uma memória imanente, ainda assim fazem parte da construção de espaços culturais da recordação muito significativos" (ASSMANN, 2001, p.318). E percebendo os espaços de memória como "um lugar praticado" (CERTEAU, [2014], p.14) possibilitando a compreensão da dicotomia ou da dialogia entre o fixo (o lugar) e o transitório (o espaço), o determinado (o lugar) e construído (o espaço) (CERTEAU, [2014]) se terce algumas considerações sobre o poema "A Uma Passante" de Charles Baudelaire [1985] e através deste uma reflexão sobre o caminhar pelas ruas da cidade urbana no contexto da modernidade.

\section{A UMA PASSANTE}

A rua em derredor era um ruído incomum. Longa, magra, de luto e na dor majestosa, Uma mulher passou e com a mão faustosa Erguendo, balançando o festão e o debrum;

Nobre e ágil, tendo a perna assim de estátua exata.

Eu bebia perdido em minha crispação

No seu olhar, céu que germina o furacão,

A doçura que embala e o frenesi que mata.

Um relâmpago e após a noite! - Aérea beldade, 
E cujo olhar me fez renascer de repente, Só te verei um dia e já na eternidade?

Bem longe, tarde, além, jamais provavelmente! Não sabes meu destino, eu não sei aonde vais, Tu que eu teria amado - e o sabias demais! (BAUDELAIRE, [1985]).

O Poema "A Uma Passante" de Charles Baudelaire compõe um dos ciclos da Obra "Flores do Mal", de 1857, o ciclo intitulado "Quadro Parisiense", que passou a fazer parte da obra apenas a partir da segunda edição, após a publicação ser censurada e retirada de circulação do mercado editorial por ser considerada uma afronta e até mesmo um atentado a moralidade da sociedade de uma Paris que se negava a enxergar-se como uma cidade em declínio, em visível decadência, no contexto de realidade descrita por Baudelaire, um centro urbano na era da modernidade (BENJAMIN, 2015).

Os poemas do ciclo "Quadro Parisiense" retratam, não como uma pintura, mas como uma descrição implícita, uma Paris em meio a uma vida moderna em uma grande cidade "[...] minada, uma cidade enfraquecida e frágil" (BENJAMIN, 2015, p. 195). Porém, mais do que a referência à cidade em si, Baudelaire nos conduz a uma reflexão sobre o sujeito urbano, sobre as pessoas em suas relações sociais na vida em uma cidade no cenário da modernidade.

Trata-se de um soneto, um poema estruturado em quatro (04) estrofes, com dois (02) quartetos, ou seja, com quatro (04) versos cada estrofe e três (03) tercetos (com três versos) num todo com cada verso com dez sílabas, ou seja, trata-se de versos decassílabos. No geral, este tipo de poema inicia-se com uma introdução apresentando o tema do poema, seguido do desenvolvimento expondo as ideias trabalhadas e a conclusão apresentada no último terceto quando se expõe o propósito principal do poema.

Sendo assim, na primeira estrofe de "A uma Passante", "A rua em derredor era um ruído incomum", Baudelaire nos expõe sua visão de uma Paris barulhenta de meados do século XIX, algo que se percebe a partir da primeira estrofe traduzindo, desta maneira, o movimento e burburinho das multidões das ruas do centro de Paris, mas que poderia ser de qualquer outra cidade a partir deste período.

Multidão com seu barulho fora do habitual trazido pela introdução dos motores e buzinas dos veículos que começavam a circular pelos grandes centros, substituindo as antigas carruagens, e ocupando os espaços que antes eram comuns para o passeio público, uma vez que as calçadas foram diminuídas cada vez mais para dar espaço para as vias de tráfego dos veículos.

Seguindo dos versos "Longa, magra, de luto e na dor majestosa", o poeta nos faz contemplar a descrição de uma figura feminina, em concordância com os adjetivos elencados, alta, esquia e soberana, símbolo da mulher parisiense. Mas, também da beleza da própria cidade, Paris, num encantamento por uma cidade mesmo em seu estado de luto, de um grande centro que destrói seu passado, majestosa mesmo diante de sua própria morte, enquanto lugar de memória.

Mas, depois o poeta nos convida a observa essa figura feminina, mais de perto, agora já definida como uma mulher, numa alegoria, uma representação da própria modernidade, "Uma mulher passou e com a mão faustosa", mulher que caminha pela rua, com sua mão esplendorosa, que passa levando abaixo todas as antigas estruturas para construir o novo, na busca do desenvolvimento contínuo e frenético que mata os artefatos de memória e que nada nem ninguém podem deter (BAUMAN, [2014]).

A modernidade surge no seio de uma sociedade que tem urgência, que tenta escapar das algemas do tempo e romper as barreiras do espaço na busca incansável e incessante por progresso e desenvolvimento. A modernidade surge quando:

[...] o espaço e o tempo são separados da prática da vida e entre si [...] o tempo tem história por causa de sua 'capacidade de carga', perpetuamente em expansão - o alongamento dos trechos do espaço que unidades de tempo permitem 'passar', 'atravessar', cobrir - ou conquistar [...] $\mathrm{Na}$ modernidade, o tempo 
moderno se tornou, antes e acima de tudo, a arma na conquista do espaço. (BAUMAN, [2014], p. 16-17, grifo do autor).

Portanto, é na modernidade que a humanidade desenvolve mais estratégias para ludibriar a passagem do tempo, buscando formas de enganar os ponteiros do relógio, de reter um grão de areia a mais na ampulheta, na tentativa de ganhar um pouco mais de tempo para construir seus projetos, nem que para isso tenha que destruir suas representações, edificações, práticas e manifestações culturais, ou seja, tudo aquilo que lhe faz memorar e/ou relembrar que o tempo passa.

"Erguendo, balançando o festão e o debrum;" a qual passa levantando e sacudindo seu deslumbrante vestido e seus acessórios, típicos da parisiense da modernidade, de vida noturna e urbana, como que se lança fora e às vistas dos observadores toda a sua antiga aparência de aristocrata que desfilava seus apetrechos pelas ruas francesas.

"Nobre e ágil, tendo a perna assim de estátua exata." Uma figura que passa pela rua com muita desenvoltura e nobreza, mesmo em meio à multidão, como se não fizesse parte desta, numa elegância de escultura monumental, indiferente ao mundo desfigurado ao seu redor.

“Eu bebia perdido em minha crispação" e nesta aparição (ou representação) assombra e encanta o poeta, como se uma estátua ganhasse vida e caminhasse entre os citadinos, conforme citando Virgílio nos diz Certeau "Reconhece-se a deusa por seu passo" (CERTEAU, 2014, p. 163), com “sua perna de estátua" pisa firme e escultural os paralelepípedos da rua na noite escura.

0 poeta se inebria com essa visão de uma modernidade que traz tantas possibilidades ao mesmo tempo em que faz desmoronar tudo o que se conhecia de sólido e permanente, onde, aparentemente, não há lugar para a memória neste novo panorama de uma sociedade (BAUMAN, [2014]) na cidade urbana.

"No seu olhar, céu que germina o furacão", figura feminina que com um olhar - sereno como o azul do céu, mas que traz em si a força destruidora do furacão - provocando um turbilhão de sensações e gerando impressões contraditórias que se configuram diante do poeta.

"A doçura que embala e o frenesi que mata" numa quase loucura em que o doce embalo de quem acalenta o descanso de uma criança, que dorme serenamente, se confunde com rebuliço violento do entusiasmo delirante dos apaixonados, num misto de sentimentos que se confrontam entre sabores suaves e o alvoroço, quase suicida, das paixões.

“Um relâmpago e após a noite! - Aérea beldade," como uma faixa de luz, que corta os céus, em meio à escuridão da noite parisiense essa etérea e bela figura, corta a nebulosa realidade da cidade fria.

"E cujo olhar me fez renascer de repente," dando a ilusão de renascimento ao artista com apenas seu visualizar, mas também gerando a incerteza de solidez, da estabilidade e permanência dos relacionamentos sociais nesta nova conjectura no contexto da modernidade, onde a eternidade ou permanência são meras ilusões, as quais só se podem encontrar nos pós-vida:

"Só te verei um dia e já na eternidade?"

Baudelaire nos apresenta sua visão de um futuro carregado de incertezas e imprevisibilidades num poema sem rimas onde se indaga, implicitamente, sobre a queda dos laços de compartilhamentos entre os sujeitos de uma sociedade em que os encontros e desencontros de estranhos nos grandes centros se tornaram rotinas de civilidade, onde os limites do tempo e espaço são constantemente desafiados (BAUMAN, [2014]).

"Bem longe, tarde, além, jamais provavelmente!" e já desanimado, mas inicialmente ainda carregando alguma esperança de futuro provável, mesmo que distante, o poeta expõe que nesta sociedade que lhe é apresentada, a qual compartilha conosco, a impossibilidade de certezas de alguma continuidade ou construção de laços ou estabelecimentos de relações de parentesco ou de familiaridade se desfaz ou se torna improvável, pois a noção de comunidade na modernidade não existe mais (BAUMAN, [2014]). 
“Não sabes meu destino, eu não sei aonde vais," na modernidade há a negação dos limites do espaço, pois o mais relevante é o caminho, seguir em frente na busca pelo desenvolvimento, quase sempre industrial ou econômico, não se é relevante saber para onde se vai apenas seguir em frente, sempre a diante na busca do mais ter (BAUMAN, [2014]).

"Tu que eu teria amado - e o sabias demais!" na modernidade não há tempo para se apegar, se envolver, tudo se esvai e passa rapidamente, mesmo que o sujeito social seja convidado, envolvido pelos encantamentos e prazeres ofertados por essa nova realidade, não há tempo para comprometimentos, para desfrutar das novas possibilidades. É preciso desapega-se, pois a modernidade está comprometida apenas consigo mesma, com o progresso e não há tempo para perder.

O tempo é o maior inimigo da modernidade e as cidades urbanas, neste contexto, são prisioneiras do progresso e seus citadinos são forçados a desapega-se de tudo os que lhes prendam ao passado, onde "tudo o que era diretamente vivido se esvai na fumaça da representação" (DEBORD, 2003, p. 13) e com isso, é preciso desapega-se, e o esquecimento e os silenciamentos tornam-se frequentes, nesta nova e, ainda presente, realidade.

A modernidade descrita na poesia de Baudelaire é fria e cruel, mas ao mesmo tempo sedutora, o poeta nos conduz, mesmo que indiretamente e quase que silenciosamente, por entre os becos de sua Paris decadente, onde sua dama que caminha etérea por entre as vielas representa uma "[...] realidade que surge no espetáculo [...] é afirmação da aparência e a formação de toda a vida humana, socialmente falando como simples aparência." (DEBORD, 2003, p. 16, 18). Espetáculo que aprisiona, encarcera os sonhos da vida do sujeito moderno.

Numa sociedade, onde "a negação da vida visível" (DEBORD, 2003, p.8) que se entregou ao vislumbre dos vícios da vida perambulante e noturna dos citadinos, que fogem de realidade negando-se a enxergar o verdadeiro cenário, que a sociedade burguesa tenta esconder. Uma sociedade em que as diferenças são acentuadas a cada dia e com mais frieza no retrato do novo homem moderno. Sociedade em que o fator humano se torna mercadoria e as relações são transitórias e vazias, onde tudo passa e tudo está alienado e condicionado a algo além de sim e só o progresso é importante, só o progresso, no sentido de ir além, ir em frente, permanece.

\section{CONSIDERAÇÕES FINAIS}

A memória é um fenômeno construído pelo sujeito social dentro do contexto do tempo e do espaço, porém não prisioneira destes.

É uma construção seletiva caracterizada pelo dinamismo e pela da transitoriedade, em um contínuo movimento de representações, de construções e reconstruções sociais. Enfim, Informação e Memória é representação.

Pode-se afirmar que a memória é constituída através das experiências vivenciadas pelo sujeito social, tanto individual quanto e acima de tudo coletivamente, sobretudo, pelas significações construídas a partir das interrelações socioculturais.

Neste artigo, se apresentaram algumas observações sobre os termos informação e memória, refletindo sobre o ato de caminhar pelas ruas, por meio da análise interpretativa dos versos do poema "A Uma Passante" de Charles de Baudelaire, entendendo a cidade como espaço de construção de sentidos, e com isso de representação e, portanto, de memória. Foram, então, apresentadas algumas considerações sobre Informação - enquanto representação social - e memória, enquanto contexto de criação de representações e interrelações dos sujeitos.

Conclui-se que a memória ocorre em um processo de construção constituída por meio do diálogo permanente entre a relação de dualidade da memória pessoal e da memória coletiva construída no contexto do sujeito enquanto ser social.

Possibilitando a configuração da identidade do sujeito social que se apresenta como ser único e individual, mas, sobretudo, como ator social que estabelece laços de pertencimento dentro da realidade de seu contexto social em que está inserido.

No poema "A Uma Passante" de Charles de Baudelaire, se pode perceber, mesmo que implicitamente, a configuração das cidades urbanas na modernidade. Num desenho sem 
floreios, numa escrita dura, fria e até mesmo cruel, apesar de sua apresentação de forma lírica e poética, numa poesia em prosa e crítica, onde a vida na cidade urbana é denota pela alienação das relações e das significações sociais. Situação que se perdura e permanece fortemente presente nas cidades dos grandes centros urbanos dos dias atuais. Tornando possível afirmar que ainda vivemos no contexto de uma modernidade, malvada e destruidora, da memória social, e rompedora dos laços de comunidade, esmagadora de tudo o que se propõe a ser eternizar ou se memorar.

Os espaços de memórias que se apresentam nas cidades, sobretudo, nos centros urbanos, se deterioram com o descaso dos atores sociais, principalmente, as representações públicas constituídas, que oficializam os discursos do Estado, mas também as mais diversas esferas das representações sociais.

Os lugares de memórias seguem lado a lado dessa triste realidade. São ruas, edificações, vias e práticas sociais que perdem sua identidade e deixam de serem referenciais as memórias locais. Basta o interesse particular de um representante do poder público para que um espaço/lugar de memória de uma cidade seja destruído ou redirecionado para uma função diversa de sua origem sem que a população local seja consultada. Possibilitando afirmar que, aparentemente, diante deste cenário, não houve preocupação em questionar para onde a modernidade levaria as memórias do lugar, houve apenas a urgência de se seguir em frente.

Os espaços e lugares de memórias compreendem os artefatos infor-comunicacionais das culturas materiais e imateriais de um povo. Os quais assumem uma implícita relação com as imposições sociais, que influenciam as interrelações do ser humano como ser social. Consequentemente, é, pois, através das construções da cultura material e imaterial que são produzidas as informações e estabelecidas às práticas sociais dentre os diversos grupos sociais, através do tempo e do espaço, estabelecendo com isso o sentido de bem cultural.

Logo, as cidades, sobretudo, em seu contexto de urbanidade, com seus itinerários e trajetórias, enquanto espaços de representação e com isso de construção de memórias; são também artefatos infor-comunicacionais memorialísticos da cultura, uma vez que expressam a memória social, que se torna presença por meio de cada interrelação de identificação e pertencimento no contexto da construção de informação vivenciada no contexto das cidades urbanas através de seus espaços de públicos.

0 ato de caminhar pela cidade é um convite ao descobrimento ou redescobrimento da vida pública, não como num folhetim ou em um universo fantasioso do blog e perfis das redes sociais. Mas, em um mergulhar na atividade da inter-relação dos sujeitos sociais na cidade e através das trocas e partilhamentos de vivências e experiências entre esses sujeitos enquanto construtores sociais; não em uma simples relação de civilidades, envolta em máscaras e encenações, mas, acima de tudo, como sujeitos coparticipes dos jogos de interação social, conscientes da relevância do ser humano como ator e construtor de informação no contexto da vida urbana da contemporaneidade.

\section{REFERÊNCIAS}

ALMEIDA, C.C. de; GUIMARAES, J.A.C. Peirce e a ciência da informação: considerações preliminares sobre as relações entre a obra peiceana e a organização da informação. VIII ENANCIB -ENCONTRO NACIONAL DE PESQUISA EM CIÊNCIA DA INFORMAÇÃO, 8,2007. Anais eletrônicos... Salvador, 2007. Disponível em: www.VIIIenancib.com.br. Acesso em: 15 maio 2009.

ARAÚJO, V. M. R. H. de. Informação: instrumento de dominação e de submissão. Ci.In., Brasília, v. 20, n. 1, p. 37-44, jan./jun. 1991. Disponível em: http://revista.ibict.br/ciinf/article/view/414/414. Acesso em: 20 jul. 2018.

ASSMANN, A. T. Locais. In: ___ _ Espaços de recordação: formas e transformações da memória cultural. Campinas: Unicamp, 2001.

AZEVEDO NETTO, C. X. de. Cultura, Identidade e Cultura material: a visão arqueológica. In: CAVIGNAC, J. Memória, Vivência, n.28, p.265-275, 2005.

. Informação e memória: as relações na pesquisa. Revista História em Reflexão,

Dourados, UFGD, v. 1, n. 2, p. 1-19, jul./ dez. 2007. 
BAUDELAIRE, C. As Flores do Mal. Rio de Janeiro: Nova Fronteira, [1985]. Tradução, introdução e notas de Ivan Junqueira.

. LES Flores Del mal [As Flores do Mal] - Introducción, traducción em verso y notas por Carlos Pujol. [Bruxelas]: Planeta, [1865]. Disponível em:

https://docente.ifrn.edu.br/paulomartins/livros-classicos-de-literatura/as-flores-do-mal-de-charlesbaudelaire Acesso em: 12 fev. 2018.

BAUMAN, Z. Tempo e Espaço. In: 107-247. [tradução Plínio Dentzien]. Modernidade líquida. Rio de Janeiro: Zahar, [2014], p.

BENJAMIN, W. Baudelaire e a Modernidade. Belo Horizonte: Autêntica, 2015. [Tradução João Barrento].

BURKE, P. Uma história social do conhecimento: de Gutenberg a Diderot. Rio de Janeiro: Zahar, 2003.

BURKLAN, M. What kind of scince can information sciense be? Journal of the American Society for Information Science and Tecnology, v.63, n.1, p.1-7, jan. 2012. Disponível em: https://onlinelibrarywiley.ez15.periodicos.capes.gov.br/doi/epdf/10.1002/asi.21656. Acesso em: 30 out. 2018.

CATROGA, F. Memória, história e historiografia. Lisboa: Quarteto, 2001.

CERTEAU, M. de. Terceira Parte - Práticas de Espaço. In: A invenção do cotidiano: artes de fazer. 22.ed. Petrópolis: Vozes, [2014], p.157-196. [tradução Ephraim Ferreira Alves].

DEBORD, G. A Sociedade do espetáculo. [S.L]: Coletivo Periferia, 2003.

DIEHL, A. A. Memória e identidade: perspectivas para a história. In: . Cultura

historiográfica, memória, identidade e representação. Bauru, SP: EDUSC, 2002, p.111 -136.

FARRADANE, J. Knowledge, information, and information science. Journal of Information Science, v. 2, p. 75-80, 1980.

FREIRE, G. H. de A.; FREIRE, I.M. Introdução à Ciência da Informação. João Pessoa: Editora Universitária da UFPB, 2009.

HALBWACHS, M. A Memória coletiva. São Paulo: Centauro, 2008, p. 224p. [tradução de Beatriz Sidou].

LE GOFF, Jacques. Memória. In: História e memória. 4.ed. Campinas: UNICAMP, 1996, p.423477. p. 535-549.

Documento/Monumento. In História e memória. 4.ed. Campinas: UNICAMP, 1996,

. Por amor às cidades: conversas com Jean Lebrun. São Paulo: Unesp, [1998]. [tradução Reginaldo Carmello Corrêa de Morais].

LOUREIRO, J.M.M. Informação, Memória E Patrimônio: breves considerações. In.: AZEVEDO NETTO, C.X. (Org.) Informação, patrimônio e memória: diálogos interdisciplinares. João Pessoa: Editora da UFPB, 2015, p. $97-107$.

LYNCH, K. A Imagem da cidade. São Paulo: Martins Fontes, 2006, p.88-92; 145-148. [Tradução Jefferson Luiz Camargo].

MCGARRY, K. O Contexto dinâmico da informação: uma análise introdutória. Brasília, DF: Briquet de Lemos/Livros, 1999, p. 1-30.

MENESES, U.B. de. Identidade cultural e arqueologia. In: Bose, A. (org.) Cultura Brasileira: temas e situações. 4. ed. São Paulo: Ática, 2002, p. 182-190.

OLIVEIRA, B. M. J. F.; AZEVEDO NETTO, C.X. de. Artefatos como elemento de memória e identidade da cultura popular: um olhar sob a perspectiva da arqueologia social. In: FECHINE, I.; SEVERO, I. (Orgs.). Cultura popular: nas teias da memória. João Pessoa: Editora Universitária, 2007, p. 27-51.

PINHEIRO, L.V. R. Gênese da Ciência da Informação: os sinais anunciadores da área. In.: AQUINO, M. A.(Org.). 0 Campo da Ciência da Informação. 2.ed. João Pessoa: Editora Universitária, 2011, p. 59-92. 
RIBEIRO, R. R. Nos Jardins do tempo: memória e história na perspectiva de Pierre Nora. [S.L.: s,n., 2000].

ROBREDO, J. Da Ciência da Informação revisitada aos sistemas humanos de informação. Brasília: Thesaurus; SSRR Informações, 2003.

SILVA, A. M. da. Informação e Cultura; Informação e Conhecimento. In: A Informação: Da compreensão do fenômeno e construção do objeto científico. Santa Maria da Freira: Edições Apontamento, 2006, p. 15 -41.

SOUZA, G. M. de. A Cidade sob um olhar - educação patrimonial e o ensino superior: experiências para o debate. In: Instituto do Patrimônio Histórico e Artístico Nacional - Paraíba; TOLETINO, A. B.; BRAGA, E. O. (Org.). Educação patrimonial [recurso eletrônico]: práticas e diálogos interdisciplinares. João Pessoa - PB: IPHAN-PB; Casa do Patrimônio da Paraíba, 2017, p. 13-27 (Caderno temático; 6). Disponível em: http://portal.iphan.gov.br/. Acesso: 28 jul. 2017.

ZEMAN, J. Significado Filosófico da Noção de Informação. In: COLÓQUIOS FILOSÓFICOS INTERNACIONAIS DE CAHIERS DE ROYAUMONT. 0 Conceito de informação na ciência contemporânea. [S.L.]: Paz e Terra, 1970, p.154179. [Tradução de Maria Helena Kühner].

Editores do artigo: Enrique Muriel-Torrado, Edgar Bisset Alvarez, Camila Barros. 